\title{
"Imagina ela nua!": Experiências de mulheres que se autodeclaram gordas
}

\author{
Camila Ferraz Jucá Menezes ${ }^{1}$ \\ $0000-0002-6201-2037$ \\ Rebeca Luisa Passos Ferreira' \\ 0000-0003-0387-0661 \\ Roberta de Sousa Mélo' \\ 0000-0003-1164-9190 \\ 'Universidade Federal do Vale do São Francisco, Petrolina, PE, Brasil. \\ 56304-917 - secretaria.gabinete@univasf.edu.br
}

\section{$-$}

Resumo: Buscamos compreender os significados que mulheres que se autodeclaram gordas atribuem às suas experiências corporais cotidianas. Foi realizada uma pesquisa qualitativa de base fenomenológica envolvendo cinco interlocutoras, com idades entre 18 a 46 anos. Utilizou-se a entrevista semiestruturada como técnica de coleta de dados. A análise do material se deu por uma perspectiva fenomenológica e apontou os preconceitos sofridos, mas também as estratégias elaboradas por essas mulheres em sua rotina. Destacamos, ao fim, a necessidade de se ampliar as reflexões sobre a temática dentro das produções teóricas feministas e dos estudos de gênero.

Palavras-chave: Corporeidade; mulheres gordas; gordofobia; feminismo.

"Imagine Her Naked!": Experiences of Women Self-identified as Fat

Abstract: We sought to understand the meanings that women self-identified as fat attribute to their daily bodily experiences. A qualitative research based on phenomenological method was carried out involving five interlocutors, aged between 18 and 46 years. A semi-structured interview was used as data collection technique. The material was analyzed from the phenomenological perspective of Moreira (2004), pointing out the prejudices suffered and the strategies developed by these women in their daily routine. It is important to highlight the need of further reflections on the subject in feminist theory and gender studies. Keywords: Corporeity; Fat Women; Fatphobia; Feminism.

\section{Introdução}

A frase que compõe parte de nosso título, "Imagina ela nua", foi proferida por um homem durante uma situação presenciada por uma das autoras deste trabalho, quando o mesmo referiuse a uma mulher gorda que, segundo ele, vestia uma roupa que não era adequada ao seu corpo. Esse episódio nos suscitou questões quanto ao consentimento cultural pelo qual a corporeidade e a sexualidade da pessoa gorda, especialmente de mulheres, se veem disponíveis às interferências alheias. Sendo assim, o presente estudo se insere no cenário mais amplo de reflexões sobre os lugares e discursos instituídos em torno dos corpos que destoam dos atributos estéticos valorizados nas configurações sociais atuais.

De modo geral, pessoas gordas também são excluídas da arquitetura das cidades e dos objetos, visto que os lugares nos meios de transporte, catracas de ônibus e metrôs, elevadores, portas e assentos de diversos estabelecimentos são artefatos que as constrangem. Tais arranjos se vinculam às relações marcadas pela gordofobia, que se refere a um processo influenciado por aparatos sociais, midiáticos, culturais e médicos e que busca reproduzir modelos de corpos ideais pautados na rejeição à gordura e na hipervalorização da magreza e/ou da hipertrofia muscular (Ramilla RODRIGUES; Vanessa ARCOVERDE, 2014). Essa dinâmica, por sua vez, está associada à fatphobia, termo que foi difundido nos Estados Unidos por militantes que indagaram, lutaram e 
colocaram-se contrários à estigmatização da pessoa gorda, conforme pontua Natália Rangel (2017).

Este estudo pode ser pensado como um recorte dos processos que marcam o corpo gordo de modo geral, no sentido de que nosso foco recai nas experiências de um grupo de mulheres que se autodeclaram gordas. De modo mais específico, nosso objetivo é compreender os significados que as mesmas atribuem às suas vivências corporais. Interessa-nos identificar, assim, como negociam seu cotidiano diante das diversas interpelações em torno de seu corpo.

Sabe-se que, dentro da trajetória ocidental, os lugares reservados às mulheres revelam a história da subordinação de seus corpos e de suas subjetividades. Ao longo desse percurso, foi forjado um modelo de subjetividade feminina pela qual a mulher foi reduzida às questões de seu corpo (Daniela ANGELI, 2004), ao passo que as atividades mentais se constituíram como uma capacidade eminentemente masculina, representada pelo modelo do homem branco, burguês e heterossexual.

Na modernidade, o corpo feminino tornou-se objeto da racionalidade científica, passando do controle e das condenações de cunho moral e religioso para a intervenção de um saber em constituição que estava emparelhado aos valores patriarcais mais antigos. Exemplo disso foi a tendência a interpretá-lo pela via do descontrole e instabilidade, o que seria explicado pela "natureza" vulnerável da mulher, conforme também nos sugere o estudo de Angeli (2004). 0 estabelecimento do discurso científico moderno foi um caminho determinante para a validação do controle técnico desse corpo e de suas expressões.

A continuidade desses empreendimentos parece revelar-se na contemporaneidade, ainda que sob outros apelos e mecanismos (Roberta MÉLO, 2012). Quanto a isso, temos a potencialização da oferta de cuidados e tratamentos destinados ao corpo feminino, assim como a coerção social para que as mulheres se mantenham jovens, belas e magras por meio de suas práticas de consumo. Não por acaso, a preocupação com as questões estéticas é um fator que tem tido forte interferência em determinadas fases de suas vidas, a exemplo da gestação, pós-parto, amamentação e envelhecimento. Desse modo, o tema deste trabalho também traz consigo uma problemática de gênero fundamental, ao expor um somatório de repressões instituídas em torno dos corpos das mulheres e de sua visibilidade.

Nessa perspectiva, as mídias digitais também têm se constituído como importante espaço de reflexões acerca da temática. Há algum tempo, a youtuber Alexandra Gurgel, ativista antigordofobia, denunciou a ação de um humorista que divulgou sua foto numa rede social, juntamente com uma legenda jocosa que fazia alusão à sua gordura (ESTADÃO, 2017), o que novamente demonstra a percepção do corpo gordo como permeável às atitudes invasivas e a sua exposição com a intenção de ridicularizá-lo.

Entre critérios de beleza e de saúde, o corpo gordo é corriqueiramente inquirido, sendo que as respostas para tais questionamentos são transitórias, uma vez que há a necessidade de se considerar o contexto histórico-social, político, econômico, bem como os padrões estéticos, as concepções de saúde, as representações de gêneros, dentre outros aspectos que caracterizam a realidade social em que os corpos estão inseridos e se constroem (Ana SILVA, 2001).

Do mesmo modo, as formas de seu disciplinamento também se transformaram, evidenciando importantes alterações na relação entre indivíduo e corpo. Por esse caminho, as representações em torno de ser gordo possuem um lugar central nos processos de subjetivação e de construção corporal que demarcam a contemporaneidade. Pode-se dizer que a lipofobia - entendida como uma "obsessão pela magreza, rejeição quase maníaca à obesidade" (Claude FISCHLER, 1995, p. 69) - faz par com a gordofobia, acentuando um inegável modelo de produção de si ancorado nas formas corporais que somos estimulados a apresentar.

Diante dessas considerações, cabe mencionar a transição de um esquema de vigilância do corpo exercida pelas instituições (família, quartel, escola, hospitais), tal como abordado por Michel Foucault (2008), para uma conjuntura em que a corporeidade se tornou objeto de responsabilidade individual, passando a ser entendida como esfera a ser administrada pelo próprio indivíduo. Em suma, o corpo passou a ser identificado cada vez mais com a própria pessoa (Georges VIGARELLO, 2012), o que torna nítida a compreensão das estigmatizações atuais em torno da pessoa gorda: "alguém sem controle ou domínio de si, que mantém o corpo feio e 'impassível' quando 'tudo' mostra que deveria mudar” (VIGARELLO, 2012, p. 15).

Na atualidade, os discursos e representações biomédicas, assim como os meios de comunicação de massa, em sua aliança com a indústria corporal, se constituem como os principais vetores da "fabricação, propagação e manutenção" dos corpos (Talita ALMEIDA, 2009, p. 14). Portanto, interessa-nos compreender, por meio das falas de nossas interlocutoras - mulheres que se reconhecem enquanto gordas -, as especificidades que marcam suas vivências corporais, identificando como elas as organizam em meio às interferências que se revelam numa rotina marcada por discursos e dispositivos que, por vezes, tendem não só a autorizar, mas justificar as mais variadas formas de intervenção sobre seus corpos e atitudes. 


\section{Percurso metodológico}

Uma vez que o estudo priorizou os significados que mulheres autodeclaradas gordas atribuem às suas experiências corporais, fez-se pertinente uma metodologia de pesquisa qualitativa e fenomenológica. A utilização do método qualitativo deve-se ao fato de a pesquisa situar-se no campo das relações sociais e da subjetividade humana, além de propiciar uma maior interação entre as pesquisadoras e as participantes. Quanto à metodologia fenomenológica de pesquisa, vislumbramos, assim como Virgínia Moreira (2004), um modelo que permitisse utilizar a "fenomenologia existencial mundana de cunho antropológico" de Merleau-Ponty como uma ferramenta críica (MOREIRA, 2004, p. 447), visto que, conforme assinalamos, nossa pesquisa priorizou a descrição das experiências do vivido pelas nossas interlocutoras no seu cotidiano corporificado.

Participaram deste estudo 5 mulheres cisgênero, maiores de 18 anos. Para definirmos nossa amostra, não nos pautamos no peso ou IMC (Índice de Massa Corporal) das participantes, mas sim no que elas próprias significavam como a experiência de "ser gorda". Nesse caso, nos apoiamos na própria abordagem fenomenológica para definirmos esse critério. O acesso a essas mulheres se deu, inicialmente, a partir da divulgação da pesquisa entre pessoas que fazem parte das redes de contato de uma das pesquisadoras, sendo solicitado que as interessadas em participar sinalizassem sua vontade via email. Além disso, utilizou-se a técnica "bola de neve", a partir da qual, ao fim da entrevista, uma interlocutora indicava outra possível colaboradora. As entrevistas foram realizadas no período de novembro a dezembro de 2017.

Utilizou-se o modelo de entrevista semiestruturada, caracterizada pela apresentação de questões previamente esquematizadas, combinando "perguntas fechadas (ou estruturadas) e abertas, onde o entrevistado tem a possibilidade de discorrer sobre o tema proposto, sem respostas ou condições prefixadas pelo pesquisador" (Maria Cecília MINAYO, 1998, p. 108). Essa flexibilidade nos permitiu explorar conteúdos que surgiam nos relatos das participantes.

As cinco colaboradoras estão em faixas etárias variadas (entre 18 e 46 anos), duas possuem ensino superior completo e três delas ensino superior incompleto. Em relação à renda per capita, houve uma variação: sendo o menor valor informado abaixo de um salário mínimo e o valor mais alto acima de cinco salários mínimos. Quanto ao estado civil, apenas uma mulher era casada. Sobre a orientação sexual, três delas se declararam heterossexuais e duas bissexuais. Para nos referirmos às interlocutoras, foram usados pseudônimos: Afrodite ( 18 anos) é estudante de Psicologia; Atena (20 anos) é estudante de Ciências Sociais; Hera (23 anos) é estudante de Psicologia; Deméter (26 anos) é engenheira agrônoma e Héstia (46 anos) é psicóloga.

A análise dos dados coletados também foi feita a partir da perspectiva fenomenológica proposta por Moreira (2004), a qual apresenta os seguintes passos: "a) Divisão do texto nativo (transcrição literal da entrevista); b) Análise descritiva do significado emergente do movimento; e c) 'Sair dos parênteses'" (MOREIRA, 2004, p. 454). As duas primeiras etapas propostas pela autora dizem respeito à transcrição e leitura dos dados coletados, bem como à avaliação e à classificação do que for significativo. Quanto à última delas, entende-se como o processo de assumir-se enquanto sujeito - ainda que também pesquisadoras - ao entrar em contato com tais experiências, posicionando-se frente aos depoimentos de forma integral, exercendo de forma plena o potencial crítico do método fenomenológico que se baseia no pensamento de Merleau-Ponty.

A proposta de pesquisa foi submetida, avaliada e aprovada pelo CEDEP - Comitê de Ética e Deontologia em Estudos e Pesquisas da Universidade Federal do Vale do São Francisco.

Os depoimentos foram analisados a partir de duas categorias principais: "As marcas da gordura nas histórias pessoais" e "As socializações do corpo da gorda". As mesmas são resultado da observação da incidência de temáticas passíveis de serem relacionadas e interpretadas a partir do referencial teórico adotado.

\section{Apontamentos históricos e té́ricos sobre o corpo gordo: necessidade de um recorte de gênero}

Em uma perspectiva histórica, Lucia Stenzel (2003) discute os modos pelos quais as concepções de beleza e de feiúra estiveram e permanecem ligados ao conceito de ser magro e de ser gordo. Segundo esta autora, formas arredondadas e corpos volumosos já foram tidos como símbolos de beleza, fartura e riqueza numa época de escassez, sendo um importante indicativo de prestígio social. No entanto, ressaltamos que essas percepções positivas coexistiram com limites socialmente estabelecidos em relação à "corpulência", e que já havia formas de censura em torno desses corpos, como era o caso das condenações dos excessos dos glutões medievais, advindas, sobretudo, do campo da moralidade religiosa (VIGARELLO, 2012). Ainda assim, a conquista de um corpo magro não se configurava como um empreendimento, tampouco se tinha a percepção patologizante da obesidade que se configurará posteriormente (Denise SANT'ANNA, 2016). 
Com o advento dos processos de urbanização e do capitalismo - sobretudo entre o fim do século XVIII e o início do XIX, a negativização do corpo gordo vai se firmando gradualmente. Nesse cenário, e de acordo com as lógicas produtivas que o caracterizaram, a exigência de corpos ativos, leves e eficientes passa a pontuar a ineficácia da pessoa gorda (VIGARELLO, 2012; SANT'ANNA, 2016). Além disso, a racionalidade científica expressa nas experimentações, métricas e validações fortaleceu o processo de desqualificação do corpo gordo. Diante disso, o interesse pelo corpo magro, de aparência leve e esguia, e sua afirmação enquanto padrão a ser seguido, consagrou-se já no início do século XX (STENZEL, 2003; SANT'ANNA, 2016). Nesse mesmo período, surgem também as famosas fórmulas de emagrecimento rápido, consolidando o combate à gordura, a qual passa a ocupar um lugar de ameaça à saúde e ao social (Rafael MATTOS; Madel LUZ, 2009).

Já no cenário cultural atual, as construções corporais têm sido fortemente orientadas por categorias e saberes definidos pela cultura fitness, materializada nos corpos que, além de magros, se pretendem "malhados", "sarados", com musculatura definida. Assistimos à divulgação massiva de conteúdos das redes sociais que vêm atravessando de forma crucial os processos de construção das subjetividades e das representações corporais contemporâneas (Natália NÉSPOLI; Joana NOVAES; Carlos ROSA, 2015), sobretudo pela influência dos ditos blogueiros(as) fitness. Nesse grupo se incluem desde profissionais do campo da saúde e da atividade física até pessoas que não têm formação nessas áreas, mas que se dedicam a um trabalho corporal que ocupa parte significativa de sua rotina, frequentemente exposta nesses veículos. Informações como o tipo de alimentação ideal, orientações para a prática de atividades físicas e hábitos cotidianos são amplamente compartilhadas, e sejam elas validadas pelo campo biomédico ou não, convergem em discursos e representações em torno da tríade corpo, saúde e beleza que culturalmente se opõe à imagem do corpo gordo.

Se nossos processos de subjetivação mais recentes nos compelem a fazer do nosso corpo o território de autoafirmação e autocontrole, os corpos gordos parecem apontar a precariedade desse projeto: desleixo, descontrole, feiúra, disfuncionalidade e falta de vontade são características comumente vinculadas à pessoa gorda (Clarissa GONÇALVES, 2004; Mirian GOLDENBERG; Marcelo RAMOS, 2002; STENZEL, 2003). Além disso, a esse corpo têm sido associados papéis sociais que tendem a lhe atribuir características jocosas e de comicidade (FISCHLER, 1995).

Os processos históricos de negativização do corpo gordo no ocidente refletem, sobretudo, uma aceitação das exigências - cada vez mais rígidas - sobre a aparência corporal, bem como a apresentação individual (VIGARELLO, 2012). Quanto a isso, sabe-se que os padrões corporais que condenam a gordura atravessam todos os gêneros. Porém, voltamos a enfatizar que o foco deste estudo são as experiências femininas de ser gorda, pois no que se incluem as diferenças elaboradas em torno dos gêneros, tem-se que "a culpabilização, por exemplo, revela-se mais severa com o corpo feminino, do qual tradicionalmente se espera flexibilidade e leveza" (VIGARELLO, 2012 , p. 12). Ainda, a repressão das pulsões e dos apetites que têm demarcado os modelos de feminilidade instituídos ao longo de nossa trajetória civilizacional - o que, por sua vez, traduz fortemente as relações conflituosas das mulheres com seus corpos - sugere que a gordura é, de fato, passível de ser lida como uma questão de gênero.

Apesar do reconhecimento das formas de controle fundadas na corporeidade e suas expressões, identificamos formas de enfrentamento e de subversão desses padrões. Jéssica Ipólito, blogueira e ativista, chama a atenção para o fato de que a luta contra a gordofobia cresceu, sobretudo, por meio da internet, por meio dos debates que têm sido promovidos por jovens mulheres (Camila BRAGA, 2017). Em sua abordagem, sugere a importância de se pensar a gordofobia interseccionada com diferentes marcadores, como gênero, raça e classe social. Ao mesmo tempo, Jéssica propõe que a gordura deve ser refletida enquanto pauta consistente do(s) feminismo(s), inclusive por se tratar de um elemento entendido como ameaçador de um projeto hegemônico de feminilidade. Afinal, como pontua Rangel (2017), a temática geralmente tem aparecido de forma secundária dentro desses movimentos.

Estudos como o de Clara Freitas et al. (2010) apontam que, em relação aos homens, as mulheres possuem maior insatisfação com a sua autoimagem. A partir de um levantamento de dados analisados em estudos nacionais e internacionais, Deíse Oliveira et al. (2014) referem-se a uma discrepância na procura pela cirurgia bariátrica de acordo com o sexo, apesar da prevalência de obesidade entre homens e mulheres ser próxima (12,4\% e 16,9\%, respectivamente). De acordo com as informações obtidas por meio das pesquisas selecionadas pelas autoras, do total de obesos no processo pré-operatório da cirurgia bariátrica, aproximadamente $80 \%$ eram mulheres. Dessa forma, cabe questionar: se, como sugerem tais estudos, não há uma diferença exacerbada quanto à prevalência de obesidade entre os sexos, o que faz com que a realização da cirurgia bariátrica ocorra mais entre as mulheres? A nosso ver, esse tipo de reflexão não pode ser desconectado das configurações até aqui apresentadas, em que se percebem mecanismos históricos pelos quais a corporeidade foi pontuada como dimensão central de uma dita "essência feminina". 
Tivemos como um dos nortes teóricos a abordagem de gênero de Joan Scott (1990), que nos direciona a entender o caráter relacional das diferenças entre homens e mulheres e a compreender as representações de masculinidade e feminilidade enquanto configurações historicamente variáveis. Além disso, a análise de Scott também se estende para as relações entre as próprias mulheres, o que se constitui como fundamental num estudo concentrado nas particularidades das experiências de nossas interlocutoras. Além disso, também tomamos como ferramenta teórica e analítica a fenomenologia de Maurice Merleau-Ponty (2006), a qual nos leva a compreender o corpo como local de elaboração de significados, ao mesmo tempo em que reconhece que nosso engajamento físico no mundo não está isolado das construções e representações culturais (nesse caso, as representações de corpo e gênero). Ou seja, significamos nossa existência a partir de nossas experiências num mundo físico e inter-humano (MERLEAU-PONTY, 2006). Essa abordagem nos foi útil justamente por termos como foco de análise as formas de interiorização, adequação e produção de sentidos que as mulheres que se reconhecem como gordas experimentam corporalmente. Do mesmo modo, foi a partir desse embasamento que pudemos analisar as respostas e formas de resistência produzidas pelas mesmas, a partir de suas experiências cotidianas.

\section{As marcas da gordura nas histórias pessoais}

Neste momento, buscaremos nos referir aos sentidos que nossas entrevistadas atribuíram às marcas da gordura ao rememorarem as diversas experiências corporais que compuseram suas histórias de vida. Para tanto, nos remetemos à abordagem de Merleau-Ponty (2006) acerca do corpo e de suas vivências cotidianas, entendendo-o como local de produção de significados. Recusando a perspectiva cartesiana pautada na ideia de supremacia da mente sobre o corpo, o autor traz, em sua fenomenologia corporal, a referência ao conhecimento produzido pela pessoa a partir do que ela experimenta corporalmente em seu cotidiano, o que é primordial para considerarmos as particularidades de cada trajetória que constituiu nosso campo de análise.

De antemão, cabe destacar que as falas da maior parte das mulheres retratam o conflito com a gordura corporal como aspecto crucial ao longo de suas vidas. Abordaram, assim, momentos vividos desde a infância até a vida adulta em que se identificaram em um corpo precário, inadequado aos padrões.

No que diz respeito às suas experiências mais antigas, a colaboradora Deméter (26 anos) relembra que, durante as brincadeiras da época de criança, costumava ser excluída das atividades que exigiam mais velocidade, situações essas quase sempre acompanhadas de apelidos criados em virtude de sua forma física. Já Afrodite (18 anos) e Atena (20 anos) destacaram as relações no âmbito familiar. A primeira relata que era chamada de gorda pela avó, tendo inclusive sua comida por ela limitada, ao passo que a segunda se refere aos diversos comentários proferidos pelo pai, tais quais Você nunca vai arranjar um namorado, porque você é gorda [...]. Se um cara quiser você, ele vai largar você por uma mulher mais magra.

Desse modo, desde o início de seus processos de socialização, especialmente em seus convívios com a família e na escola, tiveram suas identidades marcadas pelo "ser gorda" e pelo que era dito de negativo acerca disso. Para muitas, a constante depreciação de sua aparência foi um elemento primordial em seus processos de "aprender a defender-se". Vê-se, a partir dessas experiências, que logo cedo introjetaram a ideia de que os sofrimentos ligados à gordura corporal seriam uma questão a ser administrada por elas mesmas, na "solidão" de sua condição. Nenhuma delas se referiu a posturas e atitudes tomadas pela escola ou pela família em relação ao problema. Ao invés disso, nos explicaram que as primeiras significações em relação a seus corpos vieram de pessoas que representavam autoridade e com as quais possuíam um vínculo emocional, como nos indica a fala de Atena a respeito dos comentários de seu pai, e de Afrodite em relação às interferências de sua avó.

Nesses dois casos, essas mulheres se viam entre enunciados que lhes atribuíam a responsabilidade pelo próprio corpo. Essa imposição aparece nas falas como a de Deméter, que frequentemente se via frustrada, apesar de seus esforços: a mesma afirma que fez inúmeras tentativas de emagrecer (via clínica, dieta e exercícios), sem sucesso.

A esse propósito, a dificuldade em perder peso, bastante recorrente nas falas, torna-se um grande sofrimento por evidenciar a insistência de um corpo que não cede aos controles da pessoa. Do mesmo modo, a não identificação da origem de sua condição também pareceu algo incômodo, justamente por não lhe apontar o que poderia ser mais bem administrado em seu corpo.

No caso da fala do pai de Atena, podemos verificar, ainda, a ênfase num discurso sobre a gordura perpassado por uma perspectiva heteronormativa, visto que sua forma corporal Ihe impediria de "arranjar um namorado". Assim, desde cedo, a gordura lhe aparece como um atributo problematizador da feminilidade.

As situações refletidas por essas mulheres sugerem modos como os comentários alheios apontavam a precariedade do seu exercício de autocuidado. Ao longo de suas vidas, vivenciaram 
a ambivalência de amar e odiar o próprio corpo, de reconhecer-se nele ou de, a partir das desqualificações culturalmente validadas em torno de sua aparência, tomá-lo como estranho e indesejável.

De modo geral, as mulheres entrevistadas acreditam que a educação corporal que lhes foi imposta deixou fortes marcas no modo como se sentem em relação a seus corpos, mas as respostas dadas às próprias experiências não foram as mesmas. Algumas levaram para a fase adulta os constrangimentos diante do próprio corpo, enquanto outras se referiram ao rompimento com aquilo que entendem como uma lógica opressora.

De fato, de acordo com David Le Breton (2007), a infância e a adolescência se constituem como momentos marcantes no que diz respeito à socialização da experiência corporal. Considerase, por exemplo, que a criança aprende não só o que lhe é passado de forma intencional, mas também por meio dos modos de relações estabelecidos pelo primeiro espaço social. Do mesmo modo, Maria das Graças Ferriani et al. (2005), em um estudo sobre autoimagem corporal de adolescentes diagnosticados obesos, mostram que há uma grande influência da família, do social, do grupo de amigos e afins no que diz respeito ao próprio reconhecimento corporal. Diante disso, os adolescentes tendem a associar o corpo gordo como desviante, o que gera uma grande angústia diante da própria imagem.

Também Atena nos narrou uma situação vivida aos 14 anos em que, após um desentendimento, foi chamada de "preta, gorda e malvestida" por um garoto de sua idade. À época, necessitou de acompanhamento psicológico e de medicamentos para dormir. A eficácia desse tipo de violência revela arranjos sociais opressivos pelos quais atributos físicos se transformam em termos pejorativos. Essa dinâmica também marcou a trajetória de vida de Afrodite:

Eu lembro de uma coisa bem marcante da minha infância a partir de duas coisas: eu sempre fui gorda e eu sempre fui preta. E daí eu evitava muito piscina e afins por dois motivos: porque eu não queria me queimar e porque eu tinha vergonha de mostrar meu corpo (Afrodite, 18 anos).

Nestes casos em específico, percebemos a concomitância de violências como o racismo e a gordofobia, cujo mecanismo se torna nítido se considerarmos o valor positivo do "ser branca" e "ser magra", constantemente veiculado em nossos arranjos sociais, sobretudo por meio da mídia. Ao mesmo tempo, as declarações destas mulheres podem ser pensadas a partir das interpretações de Scott (1990) em torno das questões de gênero que sinalizam a necessidade de entendê-las nas relações entre as próprias mulheres. Ou seja, a abordagem do nosso tema a partir dessa perspectiva ajuda-nos a compreender assimetrias entre as diversas condições e experiência de "ser mulher".

$\mathrm{Se}$, conforme já pontuamos, o corpo das mulheres instituiu-se, historicamente, como o domínio principal pelo qual a sociedade exerce o controle de suas vidas, a experiência de ser gorda aponta importantes problemáticas sobre a expressão das mulheres em geral dentro dos arranjos sociais contemporâneos, revelando, inclusive, uma reestruturação do controle científico do corpo feminino inaugurado na modernidade. A moralidade que circunda os processos de patologização e medicalização desses corpos nos leva a reconhecer, a exemplo do que argumenta Susie Orbach (1978), a gordura como uma questão feminista.

Diante de tudo isso, as relações de poder refletidas por Joan Scott (1990) a partir da categoria gênero orientam à compreensão de como hierarquias se processam entre as próprias mulheres. Assim, embora estejamos atentas às experiências particulares e aos modos de interiorização e produção de significados que as mulheres autodeclaradas gordas experimentam corporalmente, não se pode dissociá-las dos aspectos estruturais que nos atravessam como um todo, tampouco das representações sociais de corpo e de gênero que orientam nossas interações cotidianas. Logo, os mecanismos de sujeição identificados nas experiências de nossas entrevistadas inevitavelmente apontam para um arranjo onde se revalida a subordinação das demais mulheres.

Quanto à situação narrada por Atena anteriormente, ela referiu-se, ainda, aos diferentes sentidos que atribuiu a essa mesma situação ao longo de sua trajetória. Num primeiro momento, contou que a depreciação sofrida lhe trouxe grandes sofrimentos e entraves, principalmente na vida afetivo-sexual. A respeito do início de um relacionamento, relata que passou a evitar mostrar seu corpo. Diz que, apesar de se sentir bem consigo mesma, houve um período em que não conseguia se despir diante do namorado da época.

A experiência vivida por Atena tornou-se, por um tempo, aquilo que Merleau-Ponty (2006) entende como um processo em que uma vivência precursora se torna o fundo de conduta de uma experiência atual: nesse sentido, não conseguiu se desvincular de uma experiência corporal anterior dolorosa, embora posteriormente ela tenha dado uma nova significação ao que foi vivido - isso pode ser percebido, principalmente, na ênfase dada às conversas com um amigo próximo, o que, segundo Atena afirma, Ihe ajudou a refletir sobre a situação vivenciada e a reelaborar o próprio comportamento em relação a essas lembranças negativas.

Em seus percursos com o corpo, algumas colaboradoras tiveram acesso ao que entendem como "ideais de empoderamento", pelo que puderam enxergar os movimentos opressores que até 
então conduziam sua relação com ele. Quanto a isso, nos falaram que o conhecimento das discussões sobre gordofobia e a imposição de padrões estéticos, assim como o acesso a conteúdos divulgados nas redes sociais por pessoas com quem se identificavam, foram fundamentais para sua conscientização em relação aos próprios tabus, o que lhes despertou reflexões tanto a nível individual quanto coletivo. A noção da representatividade aparece como algo importante em seus processos de ressignificação, e a partir dela, Afrodite consegue encontrar conforto: Eu sigo muito pessoas parecidas comigo [...]. É muito positivo no quesito de autoafirmação do que eu penso (Afrodite, 18 anos).

No entanto, para algumas, as marcas de uma história de conflitos com a própria imagem ainda permanecem, apesar de se reconhecerem conscientes dos arranjos sociais que fundam esse mal-estar: Acho muito bom que exista esse espaço de rede de apoio virtual direto. Eu acho muito bom, [...]; eu acho muito bonito nos outros, mas comigo eu não consigo (Hera, 23 anos).

Nesse caso, a interlocutora considera seu histórico de insatisfação corporal tão marcante que, mesmo considerando seus posicionamentos políticos em relação à pauta, enfatizando, inclusive, seu empenho em conscientizar outras mulheres, ela não consegue assimilar essa positividade para si. E, de fato, ainda que ocorram renegociações individuais em torno da experiência de ser gorda, algumas delas entendem que a representatividade, em seus casos, ainda é um processo incipiente, mesmo com as mudanças que elas apontaram.

Nesse sentido, a representação da mulher gorda, em mídias digitais, ainda reproduz e, principalmente, alimenta estereótipos do senso comum (Luiza RIBEIRO, 2016; Flávia ABREU, 2017; GONÇALVES, 2004; RODRIGUES; ARCOVERDE, 2014). Sobre isso, Abreu (2017) discute a importância das plataformas on-line, considerando seu grande alcance e poder midiático como forma de ressignificação não só do corpo gordo, mas também de outras formas de controle direcionadas à dimensão corporal e que deixam marcas importantes na vida dessas pessoas.

Ainda em se tratando das ressonâncias da marca da gordura em seus percursos, algumas entrevistadas mencionaram etapas da vida em que ela se tornou mais explicitamente uma questão mobilizadora de sentido. Héstia (46 anos), por exemplo, passa por tal vivência durante a fase adulta. Entre trabalho, casamento, gravidez e puerpério ela se viu em um ciclo de engordar, fazer dieta, emagrecer, engravidar, emagrecer na amamentação e engordar de novo posteriormente, permanecendo, por fim, com um corpo gordo. Além disso, destaca que, a princípio, o sobrepeso não marcava sua condição corporal, pois foi, na juventude, a gostosa: cintura fina, bundão, pernonas.

Em seu depoimento, Héstia nos aponta as transformações que vivenciou em relação ao seu próprio corpo em cada época. Contudo, ao final, ela vincula a experiência do "ser gorda" destacando duas vivências do corpo feminino: a gravidez e o puerpério. Entendemos que, de fato, essas fases podem ser fortemente perpassadas pelos padrões lipofóbicos no sentido de que parece haver uma ansiedade das mulheres diante das marcas estéticas trazidas por essas experiências, constituindo-se também como importantes reflexões em torno da relação gênero/ gordofobia. Percebe-se, assim, os modos como nossas simbologias da gordura cerceiam a espontaneidade desses corpos no mundo - para nos valer do sentido do movimento do ser no mundo que é central na fenomenologia corporal de Merleau-Ponty (2006). Vemos, em suma, que a depreciação socialmente legitimada de seu corpo violenta as experiências mais corriqueiras e mais íntimas das nossas interlocutoras.

\section{As socializações do corpo da gorda}

De modo geral, os relatos corroboram o argumento que apresentamos desde o início: em suas interações cotidianas, o corpo gordo vê-se constantemente invadido por palavras, olhares e ações. Sua simples presença parece acionar, a partir das mais diversas justificativas, uma série de recomendações e orientações. Contudo, há algo mencionado por Atena que muito diz a respeito da "pouca habilidade social" em lidar com o corpo gordo: [...] Eu percebo que as pessoas têm um receio de falar a palavra 'gorda' porque acham um termo pesado. [...] Plus size é só um nome bonitinho pra maquiar a palavra 'gorda', porque eles acham pejorativo (Atena, 20 anos).

Esse é um primeiro aspecto: lidar com o desconforto que seu corpo causa, inclusive quanto ao aspecto semântico. Do mesmo modo, a interlocutora revela um incômodo diante de uma tendência a se pensar a magreza como elogio:

O problema é esse: quando a gente começa a perder peso, as pessoas imaginam que é porque a gente tá se esforçando, que a gente quer estar perdendo peso. Isso me incomodou, porque ela tava elogiando por ter emagrecido como se isso fosse uma conquista pessoal. Emagrecer não é conquista, ganhar peso não é conquista (Atena, 20 anos).

De fato, retomando o argumento de Fischler (1995), percebe-se como esse jogo de palavras adquire sentido numa cultura lipofóbica e na qual a aparência corporal está constantemente no centro das interações. 
O estudo revelou, ainda, algumas estratégias de enfrentamento diante das situações de dificuldades relacionadas à sua aparência. Para algumas, seria necessário saber seguir adiante em caso de algum desrespeito ao corpo gordo. Outras afirmaram que a melhor saída, nessas circunstâncias, seria reagir com bom humor, respondendo aos comentários inoportunos num tom de deboche, ao invés de se deixar irritar.

As situações corriqueiras fizeram com que algumas criassem posturas antecipatórias, se "assumindo gorda" antes mesmo que alguém pontuasse isso. De todo modo, percebemos que a possibilidade de constrangimentos é uma constante em suas interações cotidianas. Alguns depoimentos nos sugerem que esse "assumir-se", presente muitas vezes na experiência de ser gorda, revela um mecanismo de autoproteção: Antes que alguém fale, eu mesma falo, explica uma delas. Vê-se, portanto, como sua aparência é o elemento pelo qual organizam e planejam suas interações. Necessitam administrar as impressões que seu corpo traz ao olhar do outro para que então essa relação flua de maneira menos vexatória.

Nas histórias de algumas mulheres, as críticas direcionadas foram apropriadas como estímulo para, em contrapartida, comprovar suas capacidades, reconstruindo o seu controle sobre o próprio corpo. É o caso de Hera (23 anos), que nos afirma que, apesar de se sentir mal com os comentários, costuma reagir planejando fazer dietas "mirabolantes", a fim de provar que pode ficar magra.

Por fim, e, até certo ponto, em consonância com as ideias de Merleau-Ponty (2006) a respeito das formas inesgotáveis de significações do que é vivenciado corporalmente, outras interlocutoras destacaram a necessidade de discutir e problematizar as representações sociais, enxergando no debate político sobre o corpo uma possibilidade de ressignificar as experiências de coerção vivenciadas pela pessoa gorda, muito embora determinem limites para as tentativas de diálogo: para Afrodite ( 18 anos), por exemplo, eles são estabelecidos de acordo com quem faz o comentário e de sua "disponibilidade ou paciência" para rebatê-lo.

Alinhado a essa discussão, outro aspecto presente nas falas de algumas interlocutoras diz respeito ao incômodo vivido mesmo quando a crítica é direcionada ao corpo de outra pessoa em condição semelhante, o que mais uma vez demonstra que as pessoas parecem se sentir muito à vontade para fazer do corpo gordo uma pauta. Além disso, em suas vivências, algumas mulheres frequentemente sentem o desconforto de ter seu corpo comparado ao de outras pessoas. No primeiro caso, Hera (23 anos) relata o aborrecimento de ouvir críticas direcionadas a uma artista quanto ao seu peso. Já Deméter (26 anos) revela a frequente situação de ter seu corpo comparado com o do irmão, "que é todo fitness".

A partir dessas falas, é possível ponderar sobre como o que é do outro também atravessa as suas vidas, seja um corpo semelhante ou diferente. Essa oposição parece reservar dois lugares principais para a pessoa gorda: o de culpada ou de vítima. Na primeira situação, de acordo com nossos argumentos iniciais, há uma tendência a identificá-la como descomedida, indisciplinada e fraca, adjetivações justificadas, sobretudo, a partir das representações de saúde que, por outro lado, se personificam na imagem do corpo fitness (Marcella BETTI, 2014). Na condição de vítima, no entanto, parece haver um nível de compadecimento por parte dos olhares externos quando há uma doença que justifique o seu peso. A entrevistada Héstia diz que, por vezes, se vale disso para que as pessoas não a importunem cobrando seu emagrecimento: Como se dissesse assim: 'posso ter esse corpo, posso não atender o padrão porque eu sou doente' [e as pessoas responderem]: 'ahh, se é doença, tudo bem'.

Algumas falas reiteram nosso argumento de que o discurso da saúde é uma das formas pelas quais se legitimam as intervenções em torno do corpo gordo, como também percebe Abreu (2017). A esse propósito, Afrodite e Hera destacam como o mesmo é usado como desculpa pelas pessoas para cobrarem seu emagrecimento.

Sendo assim, para além das inferências em torno de questões estéticas, as experiências cotidianas dessas mulheres são marcadas pela frequente caracterização de seus corpos como doentes, sendo que elas lidam com isso de diferentes formas. Em resumo, a ocupação de lugares e a imposição de sua presença exigem negociações constantes por parte delas, assim como modos de analisar o impacto de sua visibilidade. A gordura aparece repetidamente como a denunciadora de alguma precariedade.

De que modo, porém, assimilam essas representações desqualificadoras e socialmente instituídas? Deméter diz que não gosta dos braços e dos pés por serem muito grandes, e nem da barriga, por ser saliente. Já Hera afirma que, se pudesse mudar algo em si, perderia em torno de 10 quilos, e considera seus braços e sua barriga muito flácidos. Afrodite relata que tem aprendido a conviver e gostar do seu corpo, apesar de "eventualmente desagradar-se de sua barriga, bunda, braços e peitos", especialmente quando não há roupas que lhe caibam. Atena também diz estar aprendendo a apreciar sua condição corporal, embora se questione se não deveria pesar menos. Não se sente confortável com seus seios, sobretudo quando as roupas não os acomodam. Por fim, Héstia afirma que não há um estranhamento em relação ao próprio corpo, e que nunca considerou não gostar dele. 
A partir das considerações acima, percebe-se que suas vivências corporais são atravessadas pelo reconhecimento de partes do corpo que não as agradam e que, de certa forma, interferem em seus sentimentos em relação a ele. Em alguma medida, isso nos remete ao uso que Paola Mieli (2002) faz da noção de punctum, de Barthes, entendendo-o como o lugar do próprio corpo pelo qual a pessoa se sente olhada; o ponto de desconforto: "Trata-se de um embaraço que é [...] incômodo, um estorvo, fonte de mal-estar e de perturbação. Tem-se vontade de se desfazer, de se aliviar desse lugar do corpo para dele se livrar" (MIELI, 2002, p. 15).

Nesse aspecto, desse detalhe emergiriam sentidos porque ele falaria em nome de um todo corporal que, nos casos analisados, seria desvalorizado a partir desses fragmentos. O detalhe do excesso seria o lugar por onde imaginam serem vistas, denunciado pelos seios, barriga, braços, peso. Posto isso, essas marcas mostram a "experiência de se perceber, no corpo, um detalhe que afasta o indivíduo do corpo que ele desejaria ter" (MÉLO, 2012, p. 128).

Parece, então, que a forma de lidar com o que é rejeitado e, ao mesmo tempo, protagonista, é a renegociação diante da própria imagem. Assim, buscam conviver com o que não gostam, mas evitam olhar para essas partes. Deméter (26 anos) diz procurar diferentes ângulos e focar outros pontos de seu corpo. Hera (23 anos), por sua vez, evita ver-se no espelho sem roupa, e vestese "o mais coberta possível".

Em determinados momentos de sua vida, esses incômodos trouxeram impactos nas suas experiências de lazer, como no caso de Afrodite (18 anos), que, durante um período, deixou de frequentar determinados locais, embora explique que, posteriormente, passou a enfrentar a própria resistência:

É muito libertador, para mim, poder ir na llha do Fogo' e não ter que ficar me preocupando em esconder meu popozinho [...]; eu me permitir usar uma regatinha porque agora não tenho problema nenhum em mostrar minhas estrias (Afrodite, 18 anos).

Ainda quanto aos gerenciamentos de sua visibilidade, a moda e a forma de vestir-se se constituem como elementos importantes. Considerando que ela pode ser pensada como um campo expressivo das relações historicamente estabelecidas entre os gêneros, conforme demonstra Gilles Lipovetsky (1987) ao se referir a processos pelos quais a moda passou a ser culturalmente vinculada ao universo feminino, faz-se importante observar as evidências de seus mecanismos nas vivências das interlocutoras. Nos processos de socialização dessas mulheres, esse tema apareceu de forma proeminente, sobretudo ao fazer referência às tentativas de manter-se dentro de padrões de "normalidade" que algumas elaboram a partir da própria experiência de ser gorda: Eu me preocupo muito quando eu vou vestir uma roupa [para que] [...] as pessoas olhem pra mim e digam "ah, uma pessoa normal, não é uma pessoa obesa vestindo uma roupa inadequada, esquisita" (Hera, 23 anos).

Muitas vezes a moda foi identificada por uma lógica de exclusão, sobretudo ao desconsiderar as variações corporais. Um exemplo disso foi quando o diretor executivo da Abercrombie \& Fitch declarou que não produziriam peças em tamanho $G$ ou GG, para que a marca não fosse associada a pessoas gordas e para assegurar que só as pessoas "bonitas" comprariam suas roupas (ÉPOCA NEGÓCIOS ONLINE, 2013). Contudo, estratégias como o desenvolvimento da moda plus size trouxeram novas percepções em relação à questão da discriminação desses corpos. Ainda que esse segmento da moda não seja novidade (BETTI, 2013; SANT'ANNA, 2016), as ações mercadológicas e de marketing visando à sua promoção têm se dado de forma mais proeminente nos últimos tempos (BETTI, 2013).

Ainda assim, algumas mulheres entrevistadas possuem uma visão crítica em relação aos seus mecanismos e quanto à ideia de representatividade que se tem tentado vincular à tendência plus size. Como exemplo disso, Héstia afirma que tinha muita resistência em comprar roupa em "loja de gordo", pois - a seu ver - "é pra gordo malfeito". Todavia, reconhece que atualmente houve alguma evolução nesse segmento. Por outro lado, Afrodite afirma incomodar-se com os "cortes" dessas roupas por perceber que elas são sempre mais compostas, mais compridas: [...] Dificilmente eu encontro algo que, de primeira, me sirva. Eu tenho que comprar algo e pensar em como eu vou adaptar.

O próprio fenômeno da moda pode ser pensado a partir dos estudos de Scott (1990), sobretudo por apontar variações das maneiras como cada sociedade e configuração histórica representam os gêneros e suas relações. Cabe, então, pensar os limites e possibilidades oferecidos por esse segmento em relação aos projetos de feminilidade direcionados a quem ele busca atingir. Como sugere a fala de Afrodite, não foi ausente a referência ao fato de as roupas plus size cobrirem mais o corpo e parecerem destituí-lo de vaidade e atratividade. Isso nos remete à observação de Vanessa Profili, entrevistada por Jarid Arraes (2014), em que se refere a uma percepção bastante comum das gordas enquanto mulheres "assexuadas".

1 Uma ilha situada entre as cidades de Petrolina-PE e Juazeiro-BA. Espaço de lazer aberto à população. 
Por essa lógica, a sensualidade não seria um atributo cultivado por elas, o que parece se refletir nas roupas que são pensadas para seu corpo. Quanto a isso, faz-se pertinente pontuar que corpo, moda, estética, saúde, mídia e consumo possuem relações estreitíssimas. Atena enxerga, nos processos acima descritos, formas da mídia capitalista de se apropriar de determinadas pautas que acabam por esvaziar a luta de mulheres contra o controle de seus corpos e de suas subjetividades. A esse propósito, algumas participantes fizeram alusão ao caráter desproporcional que marca as exigências sociais em torno dos corpos femininos e masculinos. Apesar de não desconsiderarem os constrangimentos também vividos por homens gordos, elas destacaram alguns aspectos pelos quais consideram que as representações sociais em torno da gordura podem potencializar antigos mecanismos de controle do corpo feminino.

Deméter reconhece que homens gordos também sofrem, mas acredita que a mulher é mais cobrada por seu corpo: se eu fosse homem e estivesse gordo, eu não seria tão cobrado como eu tô sendo cobrada por eu ser mulher. Então, ser gorda e ser mulher é bem mais difícil de lidar. Ainda nesse sentido, Afrodite reitera o que foi dito por Deméter, e percebe uma cobrança socialmente imposta mais para mulheres do que para homens: Não é uma cobrança tão grande como imagina que seja com mulheres, porque se você for conversar com um homem no quesito de padrão, a preocupação principal de garotos é em relação mais ao pênis do que ao físico em si. Por fim, Hera argumenta que, para os homens, as exigências em torno da aparência são, de certa forma, suavizadas: Se o homem é gordo, ele não é gordo, ele é 'fofinho', 'é a barriguinha de cerveja', 'é charme' [...]. Pra mulher é sempre mais complicado; mulher tem que ter corpo escultural all the time.

Essas mulheres se veem em dinâmicas cotidianas marcadas pela concomitância de discursos sobre liberdade e aprisionamento construídos em torno da sua visibilidade. A marca corporal da gordura traz consigo a necessidade continuamente retroalimentada de provar suas capacidades em diversas esferas de sua existência, como é o caso da vida profissional: Já ouvi comentários sobre pessoas deixarem de contratar pessoas gordas porque "ah, se não quer cuidar do próprio corpo, como vai cuidar da empresa?" (Hera, 23 anos). Essas considerações coincidem com algumas das caracterizações da pessoa gorda descritas por Fischler (1995), fincadas na associação de seu biótipo à doença, preguiça e falta de controle e, por consequência, a uma reprovação moral (BETTI, 2014).

Para a maior parte das colaboradoras da pesquisa, a experiência de ser mulher e ser gorda pode ser adjetivada como "luta", algo "pesado" e "foda pra caralho". As palavras e a expressão utilizadas são atribuídas ao sentimento de que a mulher está a todo tempo sendo convocada a desempenhar um exercício de autoafirmação que se sobreponha ao que é socialmente esperado em torno de sua imagem. Por vezes, essa dinâmica foi refletida como adoecedora. Hera complementa sua fala sobre ser mulher e ser gorda dizendo que [...] é difícil. É um desafio. É angustiante. É adoecedor. Coadunado a isso, Stenzel (2003) versa sobre o quanto a pressão estética e a cultura gordofóbica são capazes de trazer sérias consequências para a pessoa, tais como isolamento social, conflitos relacionais, problemas com álcool e outras drogas, retroalimentando os problemas relacionados à comida e ao peso, o que, em parte, pode ser pensado como efeito das próprias imposições que lhes são feitas sob o discurso da saúde.

As histórias dessas mulheres nos falam, portanto, das formas de objetivação que atravessam os seus trajetos com seu corpo, mas também das reorientações no mundo que elas criaram a partir do vivido, conforme também nos inspira a leitura de Merleau-Ponty (2006).

\section{Considerações finais}

Escutar as histórias dessas mulheres foi a via encontrada para compreendermos e refletirmos sobre como práticas sociais afetam suas formas de olhar para si e constituir-se no (e com o) mundo. Os conteúdos que emergem a partir de suas experiências refletem de que modo os nossos pactos sociais são marcados por uma violência contra a espontaneidade dos corpos-pessoas em suas travessias. Revelam ideais civilizatórios que trazem em seu âmago o apagamento e mesmo a morte simbólica do que escapa aos padrões lipofóbicos.

Por muitas vezes, os constrangimentos sofridos paralisaram essas mulheres diante de si mesmas, de modo a ver seu corpo como um detalhe insuportável. Mas, justamente pelo caráter processual de nossa existência, seguiram se lançando ao cotidiano, apesar das suas feridas.

Falamos, neste estudo, da imposição de padrões não apenas estéticos, mas também de modelos afetivos, estados de felicidade e de sofrimento igualmente originados pelo mal-estar que somos culturalmente condicionados a experimentar diante de nossos próprios corpos. Em suma, os conflitos narrados por essas mulheres evidenciam, sobretudo, nossas políticas de coexistência pelas quais se demarca a indesejabilidade de determinados corpos, no que a própria presença nos espaços se torna um desafio: corpos que precisam explicar por que existem dessa forma. $O$ desafio histórico do acesso e a permanência das mulheres na vida pública parecem potencializarse na experiência fenomenológica da gordura, e ainda mais ao pensarmos nas suas interfaces 
com as questões de raça e classe social, conforme vimos, evidenciando a soma de processos de exclusão e invisibilização.

Ao mesmo tempo, nossos modelos de autogestão parecem dificultar a percepção dessas experiências como uma questão de ordem coletiva e, portanto, política: os constrangimentos vividos tornam-se mais um elemento a ser negociado pela própria pessoa a partir do cultivo da autoestima, como se os afetos e sentimentos fossem experiências totalmente privadas e não mobilizadas socialmente. Assim, a cultura nos incube a tarefa do "amor próprio" como imprescindível, mas quando não há um projeto social honestamente alinhado à espontaneidade e às marcas específicas de cada trajetória, a dignidade dessas pessoas permanece elusiva, residual.

Uma sociedade hostil, preconceituosa e gordofóbica segue violentando a existência dessas mulheres. Propomos que essas histórias possam ser pensadas não somente a partir das formas de poder que as perpassam, mas em seu potencial político de resistência diante das recusas feitas pela arquitetura dos nossos espaços e das nossas relações.

Por fim, voltamos a destacar a necessidade de se ampliar as reflexões sobre gordofobia a partir das produções teóricas feministas e dos estudos de gênero, especialmente por entendermos que as experiências de nossas entrevistadas trazem valiosas questões acerca das políticas de existência que continuam a gerenciar os corpos e subjetividades das mulheres. A nosso ver, é primordial que os debates desses campos direcionem um olhar minucioso às complexidades que interpelam as condições das mulheres num cenário em que o gerenciamento de si e o gozo pleno são cada vez mais fabricados e oferecidos pela lógica do mercado. Conforme vimos, a aversão à gordura tem se colocado como pauta da trajetória das mulheres desde as primeiras etapas de sua vida. Nesse sentido, faz-se urgente aprofundarmos as discussões sobre os lugares que ela tem ocupado nos modelos de feminilidade contemporâneos.

\section{Referências}

ABREU, Flávia Sá de. GG: Genuinamente Gostosas: um estudo das representações visuais das mulheres gordas. 2017. Trabalho de Conclusão de Graduação (Comunicação Social - Publicidade e Propaganda) - Universidade de Brasília, Brasília, DF, Brasil.

ALMEIDA, Talita Leão de. Uma beleza que vem da tristeza de se saber mulher: representações sociais do corpo feminino. 2009. Dissertação (Mestrado em Psicologia Social) - Universidade de Brasília, Brasília, DF, Brasil.

ANGELI, Daniela. "Uma breve história das representações do corpo feminino na sociedade". Revista Estudos Feministas, Florianópolis, v. 12, n. 2, p. 243-245, maio/ago. 2004.

ARRAES, Jarid. "Gordofobia como questão política e feminista". Revista Fórum, 2014. Disponível em https://www.revistaforum.com.br/digital/163/gordofobia-como-questao-politica-e-feminista/. Acesso em 08/02/2018.

BETTI, Marcella Uceda. Beleza sem medidas? Corpo, gênero e consumo no mercado de moda plus size. 2014. Dissertação (Mestrado em Antropologia Social) - Universidade de São Paulo, São Paulo, SP, Brasil.

BETTI, Marcella Uceda. "Gênero e Consumo no mercado de moda plus size". In: SEMINÁRIO INTERNACIONAL FAZENDO GÊNERO, 10, 2013, Florianópolis, USFC. Anais... Florianópolis: UFSC, 2013, p. 1-12.

BRAGA, Camila Bahia. “'Nem sempre fica evidente pelo que estão me discriminando'”. Revista Cláudia, 2017. Disponível em https://claudia.abril.com.br/noticias/jesz-ipolito-gordofobiadiscriminando-negra-lesbica/. Acesso em 04/02/2018.

ÉPOCA NEGÓCIOS. "Para afastar gordas, Abercrombie se recusa a fazer roupas largas". Revista Época Negócios, 2013. Online. Disponível em https://epocanegocios.globo.com/Inspiracao/ Empresa/noticia/2013/05/para-afastar-gordas-abercrombie-se-recusa-fazer-roupas-largas. html. Acesso em 01/02/2018.

ESTADÃO. "Ativista responde piada considerada gordofóbica de Danilo Gentili", Estadão, São Paulo, 2017. Disponível em http://emais.estadao.com.br/noticias/gente,youtuber-responde-piadaconsiderada-gordofobica-de-danilo-gentili,70002132227. Acesso em 01/02/2018.

FERRANI, Maria das Graças C. et al. "Auto-imagem corporal de adolescentes atendidos em um programa multidisciplinar de assistência ao adolescente obeso". Rev. Bras. Saúde Matern. Infant., Recife, v. 5, n. 1, p. 27-33, jan./mar. 2005. 
FISCHLER, Claude. "Obeso benigno, obeso maligno". In: SANT'ANNA, Denise (Org.). Políticas do corpo: Elementos para uma história das práticas corporais. São Paulo: Estação Liberdade, 1995. p. 69-79.

FOUCAULT, Michel. Microfísica do poder. Rio de Janeiro: Graal, 2008.

FREITAS, Clara Maria Silveira Monteiro de et al. "O padrão de beleza corporal sobre o corpo feminino mediante o IMC". Rev. bras. Educ. Fís. Esporte, São Paulo, v. 24, n. 3, p. 389-404, jul./set. 2010.

GOLDENBERG, Mirian; RAMOS, Marcelo Silva. "A civilização das formas: o corpo como valor". In: GOLDENBERG, Mirian (Org.). Nu \& Vestido: dez antropólogos revelam a cultura do corpo carioca. Rio de Janeiro; São Paulo: Record, 2002. p. 19-33.

GONÇALVES, Clarissa Azevedo. “O ‘peso' de ser muito gordo: um estudo antropológico sobre obesidade e gênero". Mneme - Revista de Humanidades, Caicó, v. 5, n. 11, p. 599-642, jul./set. 2004.

LE BRETON, David. A sociologia do corpo. Petrópolis: Vozes, 2007.

LIPOVETSKY, Gilles. O Império do efêmero - a moda e seus destinos na sociedade moderna. São Paulo: Companhia das Letras, 1987.

MATTOS, Rafael da Silva; LUZ, Madel Therezinha. "O estigma da gordura e as práticas corporais de saúde como produtoras de sentidos para o viver". Coleção Pesquisa em Educação Física, v. 8, n. 4, p. 209-216, 2009.

MÉLO, Roberta de Sousa. Da visibilidade dos corpos disformes: um estudo sobre cirurgias cosméticas malsucedidas. 2012. Tese (Doutorado em Sociologia) - Universidade Federal de Pernambuco, Recife, PE, Brasil.

MERLEAU-PONTY, Maurice. Fenomenologia da percepção. São Paulo: Martins Fontes, 2006.

MIELI, Paola. Sobre as manipulações irreversíveis do corpo e outros textos psicanalíticos. Rio de Janeiro: Contra Capa/Corpo Freudiano do Rio de Janeiro, 2002.

MINAYO, Maria Cecília S. O desafio do conhecimento: pesquisa qualitativa em saúde. 5. ed. São Paulo; Rio de Janeiro: Hucitec; ABRASCO, 1998.

MOREIRA, Virgínia. "O método fenomenológico de Merleau-Ponty como ferramenta crítica na pesquisa em psicopatologia". Psicologia: Reflexão e Crítica, Porto Alegre, v. 17, n. 3, p. 447-456, 2004.

NÉSPOLI, Natália; NOVAES, Joana Vilhena; ROSA, Carlos Mendes. "O corpo na cultura: obesidade como doença, biopolítica e normalização". DESAFIOS, Tocantins, v. 1, n. 2, p. 149-168, jan./jun. 2015.

OLIVEIRA, Deíse Moura de; MERIGHI, Miriam Aparecida Barbosa; JESUS, Maria Cristina Pinto de. "A decisão da mulher obesa pela cirurgia bariátrica à luz da fenomenologia social". Rev. Esc. Enferm. USP, São Paulo, v. 48, n. 6, p. 970-976, 2014.

ORBACH, Susie. Fat is a feminist issue: the anti-diet guide to permanent weight loss. New York: Paddington Press, 1978.

RANGEL, Natália Fonseca de Abreu. "A emergência do ativismo gordo no Brasil". In: SEMINÁRIO INTERNACIONAL FAZENDO GÊNERO \& WOMEN'S WORLDS CONGRESS, 11 e 13, 2017, Florianópolis, UFSC. Anais... Florianópolis: UFSC, 2017. p. 1-13.

RIBEIRO, Luiza Santos Junqueira. Gorda: processo de criação e realização de curta-metragem documentário. 2016. Trabalho de Conclusão de Graduação (Comunicação - Habilitação em Radialismo) - Universidade Federal do Rio de Janeiro, Rio de Janeiro, RJ, Brasil.

RODRIGUES, Ramilla; ARCOVERDE, Vanessa. Cinderela não é gorda: Análise da personagem Perséfone na novela Amor à Vida. 2014. Trabalho de Conclusão de Graduação (Comunicação Social - Jornalismo) - Universidade de Brasília, Brasília, DF, Brasil.

SANT'ANNA, Denise Bernuzzi. Gordos, magros e obesos: uma história de peso no Brasil. São Paulo: Liberdade, 2016.

SCOTT, Joan. "Gênero: uma categoria útil de análise histórica". Revista Educação e Realidade, Porto Alegre, v. 16, n. 2, p. 5-22, 1990. 
SILVA, Ana Márcia. "Corpo e diversidade cultural”. Rev. Bras. Cienc. Esporte, Brasília, v. 23, n. 1, p. 87-98, set. 2001.

STENZEL, Lucia Marques. Obesidade: o peso da exclusão. 2. ed. Porto Alegre: EDPUCRS, 2003.

VIGARELLO, Georges. As metamorfoses do gordo. História da obesidade. Petrópolis: Vozes, 2012.

Camila Ferraz Jucá Menezes (juca.camila@hotmail.com) é graduada em Psicologia pela Universidade Federal do Vale do São Francisco (UNIVASF).

Rebeca Luisa Passos Ferreira (rluisapsi@outlook.com) é graduada em Ciências Sociais pela Universidade Federal do Vale do São Francisco (UNIVASF) e graduanda em Psicologia pela Universidade Federal do Vale do São Francisco (UNIVASF).

Roberta de Sousa Mélo (rdesmelo@gmail.com) é doutora em Sociologia pela Universidade Federal de Pernambuco. É Professora Adjunta do Colegiado de Educação Física da Universidade Federal do Vale do São Francisco e membro do corpo docente do Programa de PósGraduação em Educação Física da mesma instituição. É líder do LECCORPO - Laboratório de Estudos da Cultura Corporal. Temas de atuação: Aspectos Socioantropológicos do Corpo; Gênero; Sociologia do Esporte.

\section{COMO CITAR ESSE ARTIGO DE ACORDO COM AS NORMAS DA REVISTA}

MENEZES, Camila Ferraz Jucá; FERREIRA, Rebeca Luisa Passos; MÉLO, Roberta de Sousa. "Imagina ela nua!': Experiências de mulheres que se autodeclaram gordas". Revista Estudos Feministas, Florianópolis, v. 28, n. 2 , e60118, 2020.

\section{CONTRIBUIÇÃO DE AUTORIA}

Camila Ferraz Jucá Menezes: responsável pela concepção, coleta de dados e análise de dados, elaboração do manuscrito, redação, discussão de resultados.

Rebeca Luisa Passos Ferreira: responsável pela elaboração do manuscrito, redação e revisão.

Roberta de Sousa Mélo: responsável pela orientação do trabalho.

\section{FINANCIAMENTO}

Não se aplica.

CONSENTIMENTO DE USO DE IMAGEM

Não se aplica.

\section{APROVAÇÃO DE COMITÊ DE ÉTICA EM PESQUISA}

O estudo está vinculado a um projeto de pesquisa maior, o qual foi submetido, avaliado e aprovado pelo CEDEP - Comitê de Ética e Deontologia em Estudos e Pesquisas da Universidade Federal do Vale do São Francisco, sob o CAAE 67067817.9.0000.5196.

\section{CONFLITO DE INTERESSES}

Não se aplica.

LICENÇA DE USO

Este artigo está licenciado sob a Licença Creative Commons CC-BY International. Com essa licença você pode compartilhar, adaptar, criar para qualquer fim, desde que atribua a autoria da obra.

\section{HISTÓRICO}

